\title{
YOUTH IDENTITY FROM ECOLOGICAL PERSPECTIVE BETWEEN EDUCATION AND PREVENTION
}

\author{
Jerzy Nikitorowicz \\ Krzysztof Sawicki \\ Emilia Zylkiewicz-Plonska \\ University of Bialystok, Faculty of Pedagogy and Psychology, Poland
}

\begin{abstract}
Socialisation is one of the key processes that shapes the identity of youth. This construct, which over the last century has undergone significant transformation, became a pattern for determining the purposes of upbringing (Nature vs. Nurture), or interpretative model that is used to explain character of this process from a socio-cultural perspective. On the basis of ecological framework, the concept of resilience and positive psychology, in recent years it has been developed a new approach towards socialisation - Positive Youth Development (PYD). Because of its relevance, pragmatic assumptions, this model is worth examining in terms of teleology, epistemology and methodical context.

According to the Ecological Systems Theory of Urie Bronfenbrenner the youth socialisation process is included in the micro, meso, exo and macro systems. While the socialisation process, youth experiences the interactions between these systems, which in consequence shapes its identity. An element that fits into a methodical context is the characteristic of chosen supportive, educational and preventive actions undertaken towards youth in the northeastern Poland.
\end{abstract}

Keywords: adolescents, Positive Youth Development, socialisation, youth identity.

\section{Introduction}

Motto: Young people are condemned to wander within and between multiple borders and spaces marked by excess, otherness and difference. This is a world in which old certainties are ruptured and meaning becomes more contingent, less indebted to the dictates of reverence and established truth. While the circumstances of youth vary across and within terrains marked by racial and class differences, the modernist world of certainty and order that has traditionally policed, contained, and insulated such difference has given way to a shared postmodern culture in which representational borders collapse into new hybridised forms of cultural performance, identity and political agency (Giroux, 1994, pp. 287-288). 
The identity of contemporary youth is very complex construct, interpreted from different perspectives, shaped by a number of factors. While analysing the characteristics of the young generation of the first decades in third millennium, we should note, that, development issues should be viewed from a global perspective. Living in a global village, there shouldn't be forgotten the factors determining development of children and youth in other countries or continents.

Robert M. Blum and Kristin Nelson-Mmari (2004, pp. 553-558) capture processes projecting global socialisation and development of young people in a few points: child survival, shifting demographics, international migration, rural to urban migration and poverty. They perceived that a huge increase in number of young people has resulted from the child survival initiatives implemented in the second half of XX century, especially in the developing regions of the world. This demographical change causes that global societies become even younger.

According to second factor (shifting demographics) they pointed, that the highest demographical increase is noted in less developed regions of the world, especially in Sub-Saharan Africa. Such situation is linked with cross-national migration. In the wider context these factors are underlined as influence of migration from the poor South to the rich North: income disparities between and within regions, labour and migration policies of countries, political conflicts, natural disasters, war, environmental degradation (e.g. loss of farmland), brain drain (Blum \& Nelson-Mmari, 2004, p. 554).

Obviously a global migration is only one side of the problem. In the last decades the number of youth from rural environment, looking for better future in urban areas, is also quickly increasing. This form of social adaptation is not always successful land causes many side effects, specific for migration in each dimension: unemployment, poverty, exclusion, violence, prostitution or substance abuse. Among them, poverty is a special factor, which plays a specific role. First, there is the base for migration process, motivation for searching better perspective for live. Second, unsuccessful migration increases poverty, generates marginalization, underclass, or culture of poverty (Jencks \& Peterson, 1991; Lewis, 2011; Wilson, 1987). This processes increase unsuccessful socialisation, place members of youth generation far from the social, cultural and economical mainstream.

According to these global factors the open question concerns youth identity. The aim of the study is to present the impact of socialisation process that takes place in different social environments (ecological perspective) on the development of youth identity. Additionally, it has been presented the role of good practices in the aspect of education and prevention from local institutions in northern eastern Poland in the process of developing youth identity. According to the ecological model by Urie Bronfenbrenner $(1979,1986)$ human development during adolescence is determined by the environment, defined as a set of 
connections with family, neighbourhood, peer groups, as well as the quality of the relationship with school and available forms for self-realisation. Based on these assumptions, contemporary socio-cultural environment may be perceived as uncertainty (Brown, 2015; Geldens \& Bourke, 2008) or even risk (Alaszewski \& Coxon, 2009; Beck, 1992), because of precarious social, cultural, economic, and morally-ambiguous situations. Such form of social exclusion (due to limited work and social infrastructure resources, hence creating a sense of being an outsider) has immense effects on youth (Johnston, McDonald, Mason, Ridley, \& Webster, 2000) endangering the development of one's identity (Watters, 2003), enhancing the inability to identify and engage in typical adult roles, as well as manifesting itself in the deposition of aspects such as decisions to start a family and undertaking full-time employment (Bradley \& vanHoof, 2005; Geldens \& Bourke, 2008).

Paradoxically mentioned above factors can be also perceived as the source for potential change. As Ingrid Schoon pointed Rapid social changes, especially changes in labour market opportunities, place increasing demands on young people's initiative and ability to navigate possible options and multiple demands. While previously individual lives were supposed to be more strongly shaped by structural forces, i.e., social class, gender, and ethnicity, it has been argued that young people are now increasingly expected to actively shape their own destiny (Schoon, 2007, p. 163). According to Manuel Castells identities are sources of meaning for the actors themselves, and by themselves, constructed through a process of individuation $(2010$, p. 7$)$. This proves that it is being realised in dynamic developmental relation between risk and protective factors, perceived as the area of human existence.

\section{Three Phases of Adolescence}

Richard Lerner and Lawrence Steinberg (2011) pointed to the three phases of youth development. According to these authors, the first two are solidly elaborated in the literature, but the third phase is still in progress and under construction. The first phase started at the beginning of the previous century. The turning point was the publication of the of Stanley G. Hall (1904). The author emphasises the kind of mismatch between human nature and the concepts of education of the young generation (Nature vs. Nurture). In accordance to that socialisation process of adolescents has to be attuned to social requirements. The transmission of heritage in different dimensions (e.g. tradition, history, culture and social order) is the basis for education, upbringing and socialisation.

The second phase of the theory of adolescence began half century ago with the launch of longitudinal research on life cycle and functioning of individuals in different sociocultural realities. Taken into account the multiplicity of 
perspectives, it was noted that (under the assumption of cultural relativism), the phenomenon of multiculturalism and the complexity of the social structure are the areas of adolescence. The attention is paid to the flexibility of individuals to adapt to life conditions. In this phase of theoretical reflection, adolescence is seen as a key stage of human life cycle, in which (except external, biologically determined puberty) there is also creation of own independence.

Two theoretical approaches at this stage deserve special attention. According to ecological theories the essence of analyses is the growing interaction between individuals and environment. Another theoretical approach (resilience theories) explaining the mechanism of positive adaptation to the environment, which is characterised by resistance to potential or real factors, jeopardize the development of the individuals. This is the ability to survive a stressful, difficult situation, manifested in the ability to return (the occurrence of such a situation in the future) to the normal functioning (Caldwell, Zimmerman, Bernat, Sellers, \& Notaro, 2002).

The third phase of reflection on adolescence is in an opposition to the previous assumptions, where adolescence and socialisation were seen primarily in terms of broadly interpreted problems: intoxication, sexual initiation, widely understood demoralisation. According to the above point of view, socialisation was understood as a process of solving problems. Differently, from the third phase perspective the previous strategy allows only to half-effects solving problems. Equally important is to enable youth to develop positive resources, positive identity and relations with prosocial groups. Theoretical background of the third phase is a continuation of selected theses from the second stage (resilience, ecological concept). Additionally, it pays attention to the link between applied sciences and human development. The analyses are focused on deficits and dysfunctions (risk factors) and on the potentials, opportunities (protective factors). This research activity remains in close relation with the needs of the environment. Because of the importance and significance of the third phase, we pay a special attention to this stage.

\section{Positive Youth Development (PYD)}

Rainer K. Silbereisen and Richard M. Lerner define that positive youth development is an reflection on adolescents, which has arisen because of the interest among scientists in using developmental systems, or dynamic models of human behaviour and development for understanding:

1. the plasticity of human development,

2. the importance of relations between individuals and their real-world ecological settings as bases of variation in the course of human development (Silbereisen \& Lerner, 2007, p. 3). In other words, PYD 
means better mental health and lower rates of risk behaviour and delinquency.

Positive Youth Development is perceived as three interconnected ideas:

1. youth have an inherent capacity to grow toward optimal development if given appropriate opportunity and supportive developmental ecologies;

2. youth programs orchestrate at the community level a range of developmentally appropriate supports and opportunities that build on and enhance the strengths of youth;

3. youth programs are designed to emphasize competency, skill building, youth participation, and inclusion (Benson, Mannes, Pittman, \& Ferber, 2004, p. 782).

Thriving in the field of positive development refers to changes, adolescents experience and undertake for growing into a well-adapted adult status. The proximal processes indicating thriving are academic achievement, taking over responsibility, psychological well-being, the ability to delay gratification, and appropriate strategies for dealing with problems and developmental risks (Lerner, Lerner, \& Almerigi, 2005). As outcomes of the process of thriving five attributes (the five C's) are suggested, namely intra and interpersonal competence, confidence in others and own competences, a strong character, and supportive social relationships with high levels of connection and care. Moreover, a sixth C (e.g. contribution) may be the result of the development toward an engaged, interested, and motivated adolescent (Larson \& Wilson, 2004, p. 302).

Peter. L. Benson and his colleagues at the Search Institute in Minnesota point basic framework for developmental assets dividing them into external and internal assets (Benson, 2007). According to this perspective external development assets consist of four elements:

1. Support - means, that young persons experience in family positive communication with parents; that means young person and her or his parents communicate positively, and young person is willing to seek advice and counsel from parents. They can also get support from the other non-parent adults. Adolescents also experience caring neighbours, provides a caring, encouraging environment at the school, and their parents are actively involved in helping young person succeed in school.

2. Empowerment - means, that adolescents perceive that adults in the community value youth, are given useful roles in the community, are involved in community life, feel safe at home, at school, and in the neighbourhood.

3. Boundaries and expectations - means, that adolescents' families have clear rules and react consequently, monitor the young person's 
whereabouts, adolescents' schools provides clear rules and consequences, their neighbours take responsibility for monitoring young people's behaviour. Adults and peers in environment model positive and responsible behaviour.

4. Constructive use of time - adolescents should spend three or more hours per week in practicing: music, theatre (or others arts), sport or organisations in school or community, one or more hour in religious institutions, avoid spending night with friends ,with nothing special to do".

Benson and his colleagues precise also four internal assets of PYD:

1. Commitment to learning - means, that adolescents are motivated to do well in school, actively engaged in learning, care about her or his school.

2. Positive values - adolescents should place high value on helping other people, promoting equality and reducing poverty, act on convictions and stand up for their beliefs. They should also accept and take personal responsibility, 'they should tell the truth even when it is not easy.

3. Social competencies - means, that young people know how to plan ahead and make choices, have empathy, sensitivity, and friendship skills, have knowledge and competences for contacting and building relationship with people of different backgrounds (cultural/racial/ethnic); they can also resist negative peer pressure and dangerous situations, resolve conflict non-violently.

4. Positive identity - means, that they report high level of the self-esteem, feel, that their life has purpose, think optimistic about their future.

\section{Good Practices from Environmental Context}

Gathered information is based on the desk research and the field research done in local environment in North Eastern Poland (Bialystok). All analysed methodical examples are presented in a form of four dimensions: general description, aim of the treatment, description of participants and undertaken actions.

Name of the Programme: Miejski Program "Wychowawca Podwórkowy" (Municipal Programme "Tutors at the Backyard")

1. Description of the Programme:

A large amount of risk factors that contemporary impact on societies, foster undertaking by youth risk and problematic behaviour. It takes part mainly in the youth free time. Additionally, insufficient offer of extra activities that would be universally accessible, attractive and free of charge is not conducive either to build an alternative towards risky behaviour or developing potentials and sources 
(e.g. interests, abilities, talents, psychosocial skills), which are the basis of positive youth identity.

The Programme is an example of an activity that directly relates to minimize the impact of risk factors on problematic youth behaviour. It was established in 2007 in Bialystok. The Municipal Council in Bialystok is the body that is responsible for the Programme from legal, organizational and financial perspective.

\section{Aim of the Programme:}

The aim of the Programme is to prevent socially unacceptable behaviour of children and young people by organizing their free time to develop their interests and preventive actions.

\section{Participants:}

Beneficiaries of the program are children and young people (from 5 to 18 years old) who are living at different estates in Bialystok. Programme tutors organize free time for children and youth in the afternoons on weekdays and Saturdays in the school year, as well as during the holiday season at a convenient time for the participants. The activities take place in schools (pitches, gyms, classes), housing cooperatives (housing estates squares, sports fields, rooms) and in different places, according to the subject matters.

\section{Undertaken actions:}

Educators take actions related to:

1. animation of the leisure time for children and adolescents (activities and recreational trips, themed activities concerning: cooking, dance, music, sport etc.);

2. initiation of activities aimed at teaching and learning by the young generation of social skills, including proper communication and positive relationships with themselves, in family, school, peer group and local environment;

3. help in solving various difficulties and problems (e.g. individual, family, school, legal, social) of children and youth through supportive, corrective and remedial activities.

Bialystok is one of the Polish cities where the program runs fine and fastest. Promoting the idea of the Programme, as well as a willingness to share gained experience, resulting in growing interest in the establishment of similar initiatives by local authorities in other places in the country.

\section{Centrum Sprawiedliwości Naprawczej dla Nieletnich (Restorative Justice Centre for Juveniles)}

\section{Description of the Programme:}

Creation of Restorative Justice Centre was a key element associated with fact that in our city courts did not use the opportunity and did not have the possibility 
to adjudicate educational measure (e.g. juvenile is being supervised by youth organization or minors are funnelled to perform certain activities to the victim or the community as a consequence their of misbehaviour). This was due to the lack of institutions in Podlaskie Region in which such a measure could be implemented. Therefore, in 2012, the idea of the project was developed in the Police Prevention Department in Bialystok and implemented jointly with Stowarzyszenie na Rzecz Integracji Dzieci i Młodzieży „Przyjaciele z Osiedla” (Association for the Integration of Children and Youth "Friends of the Estates").

Because of the element of restorative justice, this initiative encourage juvenile into an active participation in the process of deciding about own destiny. It teaches him to take responsibility for himself and his actions, and causes that he is more willing to implement actions in determining which he participated.

\section{Aim of the Centre:}

Restorative Justice Centre for Juveniles is a project aimed at responding to the problems of juvenile crime and its reduction in the early stages of social maladjustment. Additionally, it is important to allow a wider usage by court of educational measures (e.g. commitments to specific behaviour, youth or social organization supervision) over minors. From the perspective of minor and his parents/legal guardians, the aim is to propose an alternative towards following the traditional justice system's procedures.

\section{Participants:}

The actions in the Centre are dedicated towards minors, their parents/legal guardians and local courts. They can take part in activities that are offered in the Centre from three months up to one year. In special cases the contract can be extend.

\section{Undertaken actions:}

The activities that are undertaken in the Centre concerns better knowledge and understanding of justice system and obeying the law by minors. Additionally it is important to develop their psychological and social skills. Simultaneously, minors' parents of legal guardians participate in therapy or educational skills workshops.

The actions are undertaken in three different spheres:

1. suffering the consequences of own behaviour - each minor is involved in community works related to committed criminal act (e.g. plant a forest, clean graffiti, collect garbage, help those who are in need). Additionally, minors take part in at least one educational meeting while discussion is about risk and support factors which influence minors' behaviour.

2. modification of socially unacceptable behaviour - this action depends on the results of the previous diagnose of the deficits of the minors. It 
concerns a modification of behaviour that is socially unacceptable (e.g. different workshops and trainings).

3. strengthening positive behaviour - actions in this sphere concern searching for minors' sources and strong points such as talents, hobbies, interests (sport, theatre, writing, music, work) and its developing.

Restorative Justice Centre for Juveniles in Bialystok, was one of the first institution in Poland which implemented in its actions the basic elements of restorative justice concept.

\section{Chrześcijańskie Centrum Edukacyjne "Diament" (Christian Education Centre "Diamond")}

\section{Description of the Centre:}

Christian Education Centre "Diamond" was created because there was a lack of qualitative work with children from orphanages. The first results of the work were related even to adoption of children or establishing foster families for them. Later the need of spending free time in a constructive way by children and juveniles was observed among the educators from the Centre, that is why children and youth clubs, summer and winter camps were proposed for children and youth. Activities undertaken in the Centre develop and evaluate steadily and are adequate to the current needs of local society.

\section{Aim of the Centre:}

The main aim of the Centre is to create asylum from risk of violence, alcohol and drugs towards children and youth by e.g. educational activities, charity and caring, promotion of Christian values and nurture the Christian lifestyle, advice and assistance in the upbringing and education of children, help for orphans and abandoned children, help people with disabilities, promoting the idea of adoption family of orphans and abandoned children, counselling and assistance to families in difficult life situations.

\section{Participants:}

Centre works with children and youth from dysfunctional, poor and pathological families, which struggle with problems of alcoholism, drug addiction and unemployment. Centre also supports children from orphanages as well as children with mental disabilities.

\section{Undertaken actions:}

1. conducting two clubs for children and young people from dysfunctional families: Children's Club "Diamond" and Youth Club "Shelter";

2. organizing extra activities (e.g. plays, games, sports, watching movies, reading books, English, drama, music, art);

3. family meetings in the weekends for children from orphanages - to enable staying in private homes and experience a family atmosphere by 
children from orphanages. Thanks to this action close relationships with the families and children are established. In some cases these relations enable to establish adoptive or foster families;

4. summer and winter camps for children from orphanages and dysfunctional families in little groups from 2 to 5 children, to build close and intimate bonds;

5. rehabilitation for children with intellectual disabilities and their families;

6. nomadic and therapy camps for juveniles;

7. actions to help children from poor families (e.g. preparing Christmas gifts or purchasing school textbooks).

\section{Conclusions}

Presented methodical examples of good youth work practice are part of the analysed theoretical perspective, which is based on the environmental resources of youth resilience, understood as the strengthening protective factors and minimising risk factors. Efficiency of initiatives undertaken at the local level depends to a large extent on gained knowledge and experience, but also on implemented evaluation procedures.

According to the aim of the article, functioning of the above institutions will be discussed in pursuance of U. Bronfenbrener's ecological model:

- $\quad$ referring to the microsystem, described projects provide and reinforce positive patterns of youth activity and healthy functioning related to their attitudes and social roles;

- in the context of the mesosystem, good practices that have been presented in North Eastern Poland positively reinforce adolescents' connections with their socialization spheres. Youth relationships with family as well as peer groups, schools, local institutions are taken into account;

- the analysed projects also include the interrelationships between mesosystems (the exosystem perspective). Presented good practices involve the cooperation of particular environments or systems in which an individual does not function, but where the processes and events affecting his environment take place (cooperation of case management teams);

- $\quad$ in the macrosystem perspective of the presented programs, important aims refer towards respecting: culture; ecology; social empowerment and pursuit adolescents' responsibility for themselves and local community. 
It must be assumed that further cooperation between policy makers, tutors, social workers, social scientists should concentrate on building better conditions for youth development and will inspire to take further initiatives to support youth resilience.

\section{References}

Alaszewski, A., \& Coxon, K. (2009). Uncertainty in everyday life: Risk, worry and trust. Health, Risk \& Society, 11 (3), 201-207.

Beck, U. (1992). Risk Society: Towards a New Modernity. London: Sage.

Benson, P. L. (2007). Developmental Assets: An Overview of Theory, Research, and Practice. In R. K. Silbereisen \& R. M. Lerner (Eds.) (pp. 33-58). Los Angeles: Sage.

Benson, P. L., Mannes, M., Pittman, K. J., \& Ferber, T. (2004). Youth Development, Developmental Assets, nd Public Policy. In R. M. Lerner \& L. Steinberg (Eds.), Handbook of Adolescent Psychology (pp. 781-814). Hoboken, NJ: Wiley \& Sons.

Blum, R. W., \& Nelson-Mmari, K. (2004). Adolescent Health from an Internationa Perspective. In R. M. Lerner \& L. Steinberg (Eds.), Handbook of Adolescent Psychology (pp. 553586). Hoboken, NJ: Wiley \& Sons.

Bradley, H., \& vanHoof, J. (2005). Young People in Europe: Labour Markets and Citizenship. Bristol: Policy Press.

Bronfenbrenner, U. (1979). The ecology of human development. Cambridge, MA: Harvard University Press.

Bronfenbrenner, U. (1986). Ecology of the family as a context for human develop- ment: Research perspectives. Developmental Psychology, (22), 723-742.

Brown, P. (2015). Theorising uncertainty and risk across different modernities: considering insights from 'non-North-Western' studies. Health, Risk \& Society, 17 (3-4), 185-195.

Caldwell, C. H., Zimmerman, M. A., Bernat, D. H., Sellers, R. M., \& Notaro, P. C. (2002). Racial identity, maternal support, and psychological outcomes among African -American adolescents. Child Development, 73 (4), 1322-1366. https://doi.org/10.1111/14678624.00474

Castells, M. (2010). The Power of Identity. Malden: Wiley - Blackwell.

Geldens, P. M., \& Bourke, L. (2008). Identity, uncertainty and responsibility: Privileging place in a risk society. Children's Geographies, 6 (3), 281-294.

Giroux, H. (1994). Doing cultural studies: youth and the challenge of pedagogy. Harvard Educational Review, 64 (3), 278-308.

Hall, S. G. (1904). Adolescence. New York: D. Appleton and Company. Retrieved from https://archive.org/details/adolescenceitsp01hallgoog

Jencks, C., \& Peterson, P. E. (Eds.). (1991). The Urban Underclass. Washington DC: Brookings.

Johnston, L., McDonald, R., Mason, P., Ridley, L., \& Webster, C. (2000). Snakes \& Ladders Young people, transitions and social exclusion. Bristol: The Policy Press.

Larson, R., \& Wilson, S. (2004). Adolescence Across lace and Time. Globalization and the Changing Pathways to Adulthood. In R. M. Lerner \& L. Steinberg (Eds.), Handbook of Adolescent Psychology (pp. 299-330). Hoboken, NJ: Wiley \& Sons.

Lerner, R. M., Lerner, J. V., \& Almerigi, J. B. (2005). Positive Youth Development, Participation in Community Youth Development Programs, and Community Contributions of Fifth-Grade Adolescents: Findings From the First Wave Of the 4-H 
Study of Positive Youth Development. Journal of Early Adolescence, 25 (1), 17-71. https://doi.org/10.1177/0272431604272461

Lerner, R. M., \& Steinberg, L. (2011). The History of the Study of Adolescence. In B. B. Brown \& M. J. Prinstein (Eds.), Encyclopedia of Adolescence (Vol. 1, pp. 169-176). London: Elsevier.

Lewis, O. (2011). Dzieci Sancheza. Autobiografia rodziny meksykańskiej. Warszawa: Bona.

Schoon, I. (2007). Life Chances and Opportunities in Times of Social Change: Evidence from Two British Birth Cohorts. In R. K. Silbereisen \& R. M. Lerner (Eds.), Approaches to Positive Youth Development (pp. 157-172). Los Angeles: Sage.

Silbereisen, R. K., \& Lerner, R. M. (2007). Approaches to Positive Youth Development: A View of the Issues. In R. K. Silbereisen \& R. M. Lerner (Eds.), Approaches to Positive Youth Development (pp. 3-30). Los Angeles: Sage.

Watters, E. (2003). Urban Tribes: A Generation Redefines Friendship, Family, and Commitment. New York: Bloomsbury.

Wilson, W. J. (1987). The Truly Disadvantaged: e Inner City, the Underclass, and Public Policy. Chicago: University of Chicago Press. 